\title{
PERCEIVED INDOOR AIR QUALITY, AIR-RELATED SYMPTOMS AND VENTILATION IN FINNISH HOSPITALS
}

\author{
ULLA-MAIJA HELLGREN ${ }^{1}$, MARKKU HYVÄRINEN ${ }^{2}$, RAUNO HOLOPAINEN ${ }^{1}$, and KARI REIJULA ${ }^{1,3}$ \\ ${ }^{1}$ Finnish Institute of Occupational Health, Helsinki, Finland \\ ${ }^{2}$ Insinööri Studio Oy, Lappeenranta, Finland \\ ${ }^{3}$ Tampere School of Public Health, University of Tampere, Tampereen yliopisto, Finland
}

\begin{abstract}
Objectives: Good ventilation is more important in hospitals than in many other buildings. The objective of this study was to evaluate the effect of the condition, performance and modernity of ventilation systems on the perceived indoor air quality (IAQ) and the indoor air-related symptoms of hospital personnel. Materials and Methods: An inspection and evaluation graded on a 1 to 3 scale of the condition, performance, and modernity of the ventilation systems was carried out in ten central hospitals in Finland. The perceived IAQ and the related symptoms were collected by means of an indoor air questionnaire survey among the workers in these hospitals. Results: The condition, performance and modernity of the ventilation systems were good in $40 \%$ of the hospitals included in the research and poor in another $40 \%$ of them. In hospitals where the majority of the ventilation systems were assessed to be good, the prevalence of the indoor air-related complaints and symptoms was lower than in hospitals where the majority of the ventilation systems were assessed as needing extensive repairs. Conclusions: The condition and performance of the ventilation systems in hospitals had a significant impact on the perceived IAQ and the symptoms observed among the employees in Finnish hospitals. Therefore, it is important that hospital ventilation systems are maintained properly and regularly. Furthermore, they should be renovated, at the latest when their technical lifespan expires.
\end{abstract}

Key words:

Evaluation of ventilation, Indoor air questionnaire, Perceived indoor air quality, Health care workers

\section{INTRODUCTION}

Hospital activity induces special requirements on the quality of the indoor air. Good indoor air quality (IAQ) in hospitals is important to protect the patients, personnel and visitors from dangerous airborne contaminants [1-2]. IAQ is affected by the efficiency of ventilation, the type of work taking place in the given facilities, the structure of the facilities, the tightness of the building envelope, and the sources of contaminants in both indoor and outdoor air. The efficiency of ventilation, supply air filtering, air pressure relations between the facilities and the tightness of the building envelope all play a central role in controlling indoor air contaminants. Hospitals are composed of different facilities in which the required conditions for indoor air differ significantly from one another. For example, office departments should meet the IAQ standards for regular office buildings. On the other hand, hospitals include very demanding facilities such as operating rooms and hospital pharmacies with much stricter IAQ requirements.

Finland is a geographically large but sparsely populated country divided into 20 hospital districts. Each hospital

Received: June 28, 2010. Accepted: September 20, 2010.

Address reprint request to U-M. Hellgren, Finnish Institute of Occupational Health, Arinatie 3 A, FI-00370 Helsinki, Finland (e-mail: ulla-maija.hellgren@ttl.fi). 
district has one central hospital formed by a building cluster typically consisting of 3-6 buildings. The main buildings of the central hospitals were primarily built in the period 1950s-1970s, and the supplementary buildings have been added to most central hospitals over the past decades. Some central hospitals were built as a single construction project from 1970s to 1980s. The number of employees in a single central hospital oscillates between 1000 and 5000 . The ventilation systems of the hospital buildings were usually built using the ventilation technology typical to the time of their construction. The energy efficiency of the buildings and ventilation systems was only taken into account after the 1970s energy crises.

Finnish hospital workers have reported more indoor air problems and indoor air-related symptoms than the staff employed in the office buildings [3]. The prevalence of the indoor air-related problems and symptoms was higher when the working facilities needed immediate repairs [4]. The prevalence of the indoor air-related symptoms has been high also in Swedish geriatric hospitals [5].

The aim of the present study was to evaluate the perceived IAQ and symptoms of the hospital workers in relation to the condition, performance and modernity of the hospital ventilation systems.

\section{MATERIALS AND METHODS}

\section{Central Hospitals}

The study was carried out in ten central hospital districts, and altogether 30 hospital buildings, located evenly throughout the country and built between the 1940s and 2000s were included in the research.

\section{The Condition, Performance and Modernity of the Ventilation Systems}

Each hospital building had several, in some cases even tens of different ventilation systems. The age and condition of a ventilation system did not necessarily correspond to the age and/or condition of the building itself; the same building might have both new and modern ventilation systems, as well as old systems that were in need of extensive repairs. Therefore, the evaluation was carried out "en bloc" as a multi-stage survey including a background questionnaire, inspections, and interviews with both persons responsible for the maintenance of the ventilation systems and the building occupants. The present study evaluated the condition, performance, hygiene, sufficiency and need for improvement of the hospital ventilation systems. The inspection utilized the knowledge of the hospitals' technical personnel combined with on-the-spot inspections. The ventilation sufficiency was estimated based on the design plans, measurements records or information from the building automation system.

The inspection was carried out in the order illustrated in Table 1. The hygiene of the systems was examined visually. The evaluation included, a visual assessment of the cleanliness of the air handling units and ducts, possible fiber sources inside the ventilation systems, the location of the outdoor intake, possible moisture damage to the air handling units and the filtration class of the supply air. Other elements assessed during the research examination included: overall cleanliness of the machine room, cleanliness and accessibility of the access routes and maintenance practices. Samples were collected from the supply air ducts to assess the amount of man-made mineral fibers. The inspection and subsequent analysis of the data collected in each hospital took approximately a week. The professionals involved in the survey had many years of experience in evaluating the condition, performance, and modernity of ventilation systems in buildings with an indoor air problem. The same professionals carried out inspections in all hospitals.

The results were collected into a summary that was reviewed together with the hospital technical staff during the final interview. The condition, performance and modernity of the ventilation systems in the entire hospital complex 
Table 1. Inspection stages

\begin{tabular}{|c|c|}
\hline Stage & Inspection task \\
\hline 1 & $\begin{array}{l}\text { Background information on the hospital ventilation systems was collected before the process from the personnel } \\
\text { responsible for them before the visit in each hospital }\end{array}$ \\
\hline 2 & $\begin{array}{l}\text { The technical personnel of the hospital was interviewed. The interview focused on experiences related to using } \\
\text { the ventilation systems, the maintenance practices and the cleaning operations }\end{array}$ \\
\hline 3 & Getting acquainted with the hospital building and its ventilation systems with the help of the hospital technical personnel \\
\hline 4 & $\begin{array}{l}\text { The inspection: } \\
\text { - technical specifications of equipment } \\
\text { - location of the machine room } \\
\text { - basics of the systems } \\
\text { - systems' repairs and modifications } \\
\text { - hygiene level of the ventilation equipment and ducts }\end{array}$ \\
\hline 5 & The hospital employees were interviewed concerning the perceived IAQ \\
\hline 6 & Summary of the inspection and report on the results \\
\hline
\end{tabular}

Table 2. Evaluation criteria for inspection

\begin{tabular}{|c|c|}
\hline $\begin{array}{l}\text { Evaluation of the condition, performance } \\
\text { and modernity of the ventilation systems }\end{array}$ & Evaluation criteria \\
\hline Good and modern & $\begin{array}{l}\text { - Age of the ventilation system is below } 20 \text { years } \\
\text { - The ventilation system is mostly in good condition } \\
\text { - Air flow rates and the ventilation equipment are suitable for hospital premises }\end{array}$ \\
\hline Need for repairs/improvement & $\begin{array}{l}\text { - Age of the ventilation system is below } 30 \text { years } \\
\text { - The ventilation system is in such good condition that its partial replacement or partial } \\
\text { repairs are beneficial from both the economic and performance perspective } \\
\text { - Air flow rates and the ventilation equipment are mainly suitable for hospital premises }\end{array}$ \\
\hline Need for extensive repairs & $\begin{array}{l}\text { - Technical lifespan of the ventilation system has expired (over } 30 \text { years old) or the } \\
\text { system is in such poor condition that partial repairs are no longer feasible } \\
\text { - Age of the ventilation system is over } 20 \text { years and it does not meet the purposes } \\
\text { of the facilities } \\
\text { - Age of air ventilation system is over } 20 \text { years and it would be well-advised to replace it }\end{array}$ \\
\hline
\end{tabular}

were classified on a 3-point grading scale. Table 2 presents the evaluation criteria. The classification shows an overview of the condition, performance and modernity of the ventilation systems at each of the hospitals as a whole.

\section{Indoor Air Questionnaire Survey}

Complaints and symptoms relating to IAQ and the hospital environment were collected using a standardized questionnaire [6,7] in the spring of 2004. The questionnaire was sent to the hospital staff $(\mathrm{n}=5598)$ working in different departments of the ten targeted central hospitals. Each hospital received questionnaires proportionally to the entire staff of the facility. On average, one third of the total personnel received the questionnaire. The number of employees was related to the staff total in such a way that one third of the total personnel received the questionnaire. The questionnaires were sent to patient wards, outpatient clinics, laboratories, to operating room staff and to 
radiology units. The purpose of the survey was to collect information on environmental complaints and symptoms covering the period of three months preceding the survey. Only the symptoms reported on a weekly basis and those reported as connected to the work environment were taken into consideration. The questionnaire also assessed the prevalence of allergic diseases and the functionality of the work arrangements.

\section{Statistics}

Statistical operations that included the differences in proportions with the use of chi-square tests were calculated using an SAS program package (version 9.1, SAS Inc, Gary, NC, USA). The differences were calculated between the hospitals with good ventilation and the hospitals with poor ventilation.

\section{RESULTS}

\section{Condition, Performance and Modernity}

\section{of the Ventilation Systems}

Figure 1 presents the results of the ventilation systems evaluation in each inspected hospital.

Based on the survey summaries the central hospitals were further ranked as follows: good, if the majority of the ventilation systems were good and modern (hospitals 7-10 in

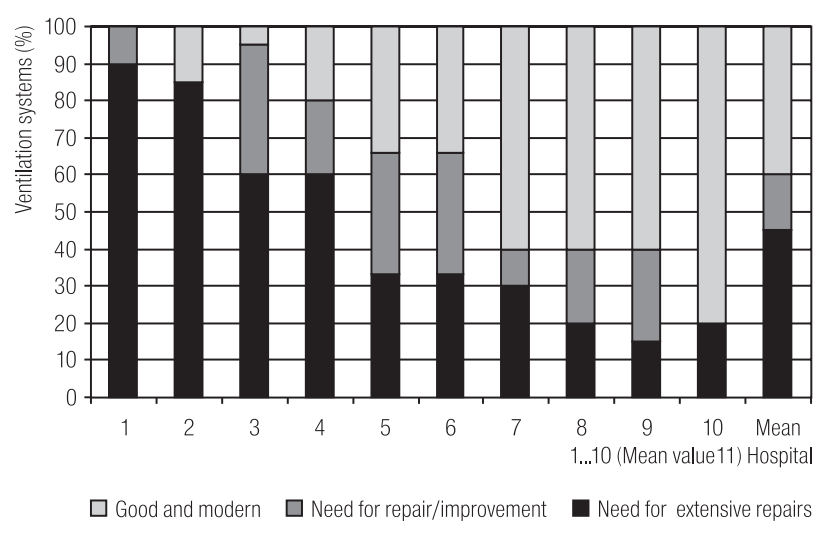

Fig. 1. The condition and modernity of the ventilation systems in the ten targeted hospitals.
Figure 1); poor, if the majority of the ventilation systems were in need of extensive repairs (hospitals 1-4 in Figure 1); and moderate, if there were approximately as many good and modern ventilation systems as those in need of extensive repairs (hospitals 5-6 in Figure 1).

Four of the inspected hospitals had ventilation systems en bloc in good condition, other four in poor condition, and two in moderate condition.

According to the inspection, the most common ventilation problems included insufficient ventilation of facilities, uncontrollable temperature conditions, draught, and problems with removing impurities worsened by the lack of local extraction, as well as insufficient ventilation system hygiene.

\section{Results of the Indoor Air Questionnaire Survey}

A total of 3739 hospital workers participated in the survey (response rate $68 \%$ ).

The results of the indoor air questionnaire are presented in Figures 2 and 3. Figure 2 illustrates the weekly environmental problems reported by the survey participants. Figure 3 presents the reported weekly symptoms.

Hospital workers occupying the buildings with good ventilation (1054 respondents) reported the least frequently

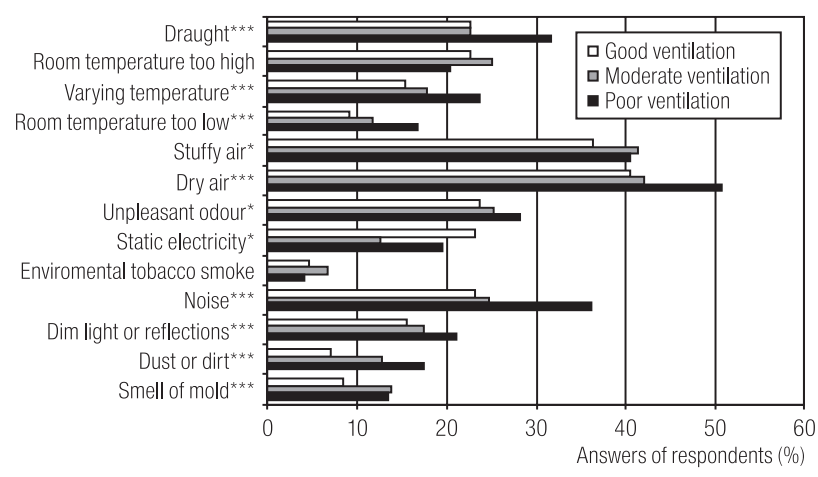

P-value was calculated for the differences between good and poor ventilation.

* Statistically almost significant $(\mathrm{p}<0.05)$;

*** statistically very significant $(\mathrm{p}<0.001)$.

Fig. 2. Environmental complaints in relation to the condition and modernity of the ventilation systems. 


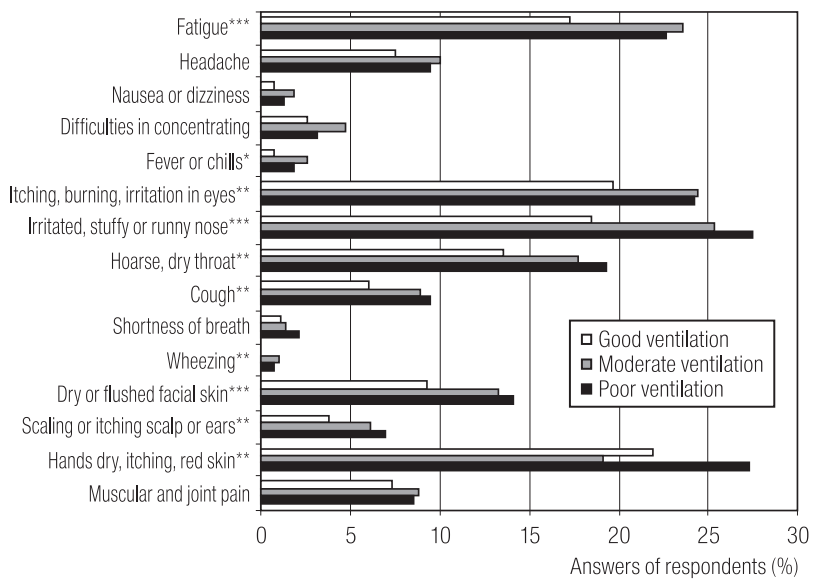

P-value was calculated for the differences between good and poor ventilation.

* Statistically almost significant, ** statistically significant,

*** statistically very significant.

Fig. 3. Indoor air-related symptoms of hospital workers in relation to the condition and modernity of the ventilation systems.

of all the environmental complaints, except for static electricity. In hospitals with poor ventilation (1843 respondents), the workers reported the most often all the environmental complaints, except for environmental tobacco smoke and too high room temperature. The difference between the hospitals with good and poor ventilation was very significant regarding draught $(\mathrm{p}<0.001)$, dry air ( $p<0.001)$, too low or varying temperature $(p<0.001)$, noise $(p<0.001)$, dim light or reflections $(p<0.001)$, dust and dirt ( $\mathrm{p}<0.001)$, and the smell of mold $(\mathrm{p}<0.001)$. In addition, the staff employed in the hospitals with good ventilation reported the least frequently of all symptoms relating to indoor air. The difference between the hospitals with good and poor ventilation was very significant regarding irritated, stuffy or runny nose $(\mathrm{p}<0.001)$, hoarse, dry throat $(\mathrm{p}<0.001)$, and dry or flushed facial skin $(p<0.001)$. The difference regarding other irritation symptoms, such as hands dry, itching, red skin ( $p=0.002)$, scaling or itching scalp or ears $(p=0.001)$, wheezing $(p=0.004)$, cough $(p=0.002)$, itching, burning, irritation in the eyes $(\mathrm{p}=0.005)$, and fatigue $(\mathrm{p}=0.001)$ was also significant.
Workers employed in the hospitals with moderate ventilation quality (842 respondents), made complaints less often than those in hospitals with poor ventilation, but more often than those in hospitals with good ventilation. Indoor air-related symptoms were reported more often than in hospitals with good ventilation, and almost as often as in poorly ventilated hospitals.

Allergic rhinitis was reported slightly less often in hospitals where the ventilation was ranked as good than in hospitals where the ventilation was evaluated as moderate or poor $(p=0.05)$. As regards asthma, allergic dermatitis or atopic conditions, there were no statistical differences among the groups. The same number of recurrent respiratory tract infections during the previous 12 months was reported in all hospitals irrespective of the conditions of the ventilation systems. The performed kind of work was regarded as interesting and inspiring more often in hospitals where the ventilation systems were considered good, than in hospitals where they were poor $(p=0.01)$. There were no differences among the groups regarding social support, influence over one's work and work intensity.

The condition of the building itself was evaluated, on average, as being as good in hospitals with good ventilation as in hospitals with poor ventilation (Figure 4).

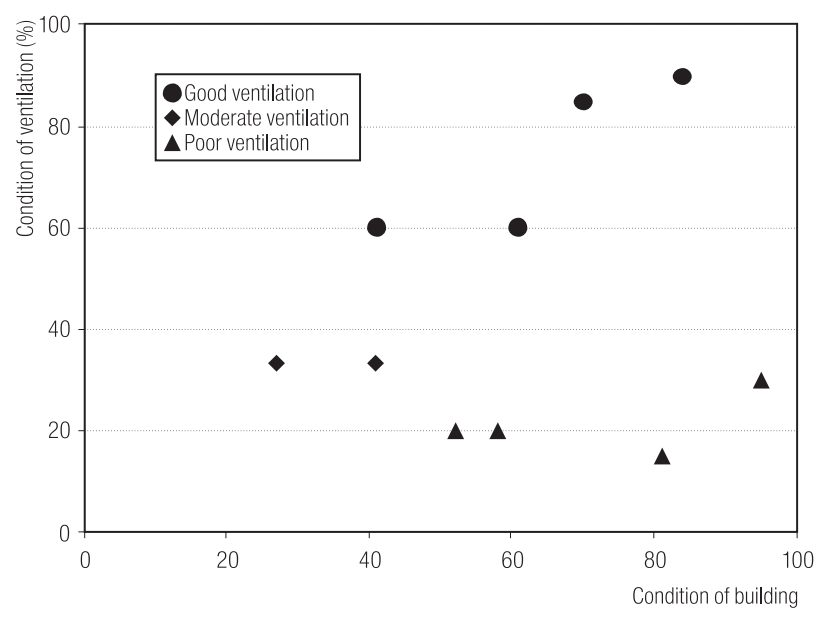

Fig. 4. Correlation between the condition of the ventilation systems and the building itself (\% good). 


\section{DISCUSSION}

Studies on hospital ventilation usually focus on the ventilation in special facilities, especially operating rooms [8-10]. The present study evaluated the hospital ventilation systems in their entirety and their effects on the perceived IAQ and the related symptoms reported by the hospital staff.

According to the inspections, the main problems concerning hospital ventilation included insufficient ventilation and lack of good instructions for ventilation design and maintenance. The importance of good ventilation had not been prioritized high enough to maintain good IAQ until during the last few decades. Due to the lack of proper design instructions, many shortages or mistakes had been made in the design of the ventilation systems leading to e.g., bare fiber sources in the system. In Finland there are only the minimum demands given in the National Building Code of Finland (Finnish Ministry of the Environment, 2003), and some space specific guidelines, e.g., for hospital pharmacies provided by the National Agency for Medicines. All investigated ventilation systems fulfilled or exceeded the existing design criteria at the building time. Since then, the demands of the IAQ have increased. Uniform design criteria for ventilation in different hospital spaces should be ensured.

The condition of the present hospital buildings is better than the condition of the ventilation systems. The reason for this might be that the problems with ventilation are not visible to the user in the same way as the problems with the building itself. Maintenance practices and the actual maintenance of the ventilation systems have been insufficient. Moreover, the design of the ventilation systems did not take into account the maintenance aspect to a sufficient degree.

The expected life span of the ventilation systems in hospitals is about 20-30 years, usually not as long as the age of the building. They should be renovated before the IAQ problems turn to complaints.
An experienced consultant can evaluate the condition, performance and modernity of a ventilation system bearing in mind the demands of the facility. However, the person evaluating the ventilation conditions needs to be educated, interdisciplinary and trained in the methods of evaluating such conditions.

Based on the present survey, it can be stated that the hospital employees considered IAQ as better and the number of reported symptoms was lower in the hospitals with good ventilation than in the hospitals with poor ventilation. The condition of the building itself was, on average, evaluated as good both in hospitals with good ventilation and in hospitals in which the ventilation systems needed extensive repairs. Thus, in the present assessment the perceived IAQ was related to the condition of the ventilation systems.

Poor ventilation seemed to be particularly associated with draught, dry air, varying or low room temperature, noise, dim light or reflections, dust and dirt and the smell of mold.

Numerous follow-up questionnaire surveys showed that when ventilation is made more effective, the number of complaints concerning draught increases. The present study shows, however, that properly working ventilation does not cause the sense of draught.

Perceiving indoor air as dry was quite a common complaint in all hospitals. Indoor air is perceived as dry during the heating season. In an earlier study on the condition of the same buildings, dry air correlated with the need to repair moisture damage [4]. In the present study, dry air correlated with the performance of the ventilation systems. There are many impurities in hospital air resulting from the hospital activity or from moisture damage which is common in hospital buildings [4]. Good ventilation dilutes the concentrations of impurities much more effectively. Hospital activity is the source for multiple requirements concerning the thermal conditions, and ventilation plays the major role in controlling them. 
Noise was a common complaint along with poor ventilation in the present study. It was not examined where the noise came from. In the previous study, noise did not seem to have any connection with the need for repairs concerning the building itself [4]. Hospital activity may cause noise problems, but the respondents performed the same kind of activities in hospitals with poor and good ventilation. It is suggested that a poorly working ventilation system can even be involved in how the noise problem is perceived. Also Nordstrom in his study found out that ventilation noise in hospitals ought to be reduced [5].

Both hospitals with good and poor ventilation differed from one another also in the aspect of lighting, which can be explained by the fact that ventilation repairs were usually given the lowest priority. The present study found no hospitals where the ventilation systems were in good condition, but the building itself was in poor condition.

The survey participants reported more dust and dirt on surfaces in hospitals with poor ventilation than in hospitals with good one. This may be connected with the pressure relations within the building and the transfer of impurities through leaks in the building envelope. The quality of cleaning was not the main focus of this study. In the previous study, it was found that hospital staff reported less dust and dirt than staff in the office buildings [3]. Dust and dirt reports also clearly correlated with the need for repairs [4]. On the other hand, surfaces that need to be repaired are more likely to look dirty than new surfaces.

In the present study the smell of mold was experienced more often in hospitals with poor ventilation (Figure 2). Assuming that hospitals with either good or poor ventilation have equal extent of moisture damage as shown in Figure 4, it can be said that good ventilation removes the associated odor problems more efficiently. However, the difference was not so clear concerning other unpleasant odors.
In the present study, the stuffiness of indoor air was not as clear an indicator of the quality of ventilation, as it is commonly understood to be. Airflow rates are usually higher in hospitals than in office buildings, which may explain such situation.

Static electricity was reported more often when ventilation was evaluated as good. The survey was conducted during the heating season, when the relative humidity levels in the supply air were low. Increased ventilation efficiency removes moisture in the indoor air and at the same time it dries it, which may cause static electricity. Nordstrom et al have shown that moderate air humidification during the winter in colder climates reduced the number of complaints of static electricity reported by hospital staff [11]. As regards the reported symptoms, those that correlated best with the state of the ventilation systems included irritation of the nose, dry or flushed facial skin and fatigue. Other irritation symptoms like hoarse, dry throat, itching, burning, irritation in the eyes, cough, wheezing, hands dry, itching, red skin and scaling or itching scalp or ears correlated significantly with ventilation as well. The most probable explanation for the irritation symptoms is the fact that the impurities remain in the indoor air when ventilation is poor. In the previous study, also fatigue was associated with insufficient ventilation [12].

Allergic individuals report indoor air-related symptoms more often [7]. In the present survey, the personnel in hospitals with poor ventilation reported slightly more cases of allergic rhinitis than persons working in a hospital with good ventilation, which may also partially explain the experienced symptoms.

Previous studies $[13,14]$ showed that poor ventilation increases the number of short-term sick leaves. However, in the present study, the number of reported recurring respiratory tract infections among the staff did not seem to be related to the ventilation conditions. On the other hand, in the previous study, the need for repairs in hospital buildings increased the number of recurring respiratory tract infections [4]. 
In the present study, the hospitals with good and poor ventilation differed from one another concerning one factor related to work arrangements (regarding work as interesting and inspiring). This may be a minor confounding factor, but it does not explain the present results. However, if the employees find their psycho-social work environment pleasant, they usually report disturbing symptoms less often [15].

Poor and insufficient ventilation decreases the efficiency and productivity at work and affects the working atmosphere [16,17]. In addition, poorly working ventilation may pose a great health risk factor for some patients [3]. The role of airborne pathogens in hospital infections has been underrated [18]. Hospital buildings are under constant repair works and renovation dust commonly contains microbes, for instance Aspergillus genus mold spores [19]. A hospital infection caused by the Aspergillus fungus may also spread through the ventilation systems [20]. The role of ventilation in controlling the spread of impurities cannot be overemphasized. The renovation of the ventilation systems in hospitals is expensive and difficult and therefore such projects are often postponed.

A modern and well-functioning ventilation system increases patients' safety, decreases the number of indoor air symptoms reported by hospital employees and improves working atmosphere, as well as work efficiency.

Based on the present study, it can be stated that ventilation has a significant impact on the perceived IAQ and indoor air-related symptoms in hospitals. More attention should be paid to hospital ventilation, not only in special facilities (e.g., operating rooms, pharmacies, laboratories), but in other areas in hospitals as well. Uniform design criteria for the ventilation systems in different hospital spaces are needed. The expected life span of the ventilation systems in hospitals is usually not as long as the age of the building in which they are located. They should be renovated before any IAQ problems turn to complaints.

\section{ACKNOWLEDGEMENTS}

Authors would like to thank Mr. Eero Palomäki for his contribution to data analysis and Mr. Henri Riuttala for his statistical assistance.

\section{REFERENCES}

1. Kalliokoski P, Luscuere P, Streinfel A. Indoor Air Quality in Hospitals and Other Health Care Facilities. ISIAQ task force reports. ISIAQ; 2003.

2. Li Y, Leung GM, Tang JW, Yang X, Chao CY, Lin JZ, et al. Role of ventilation in airborne transmission of infectious agents in the built environment - a multidisciplinary systematic review. Indoor Air 2007;17(1):2-18.

3. Hellgren U-M, Reijula K. Indoor-air-related complaints and symptoms among hospital workers. Scand J Work Environ Health 2006;32(Suppl 2):47-9.

4. Hellgren U-M, Palomäki E, Lahtinen M, Riuttala H, Reijula K. Complaints and symptoms among hospital staff in relation to indoor air and the condition and need for repairs in hospital buildings. Scand J Work Environ Health 2008;34(Suppl 4): 58-63.

5. Nordstrom K, Norback D, Akselsson R. Influence of indoor air quality and personal factors on the sick building syndrome (SBS) in Swedish geriatric hospitals. Occup Environ Med 1995;52(3):170-6.

6. Andersson K. Epidemiological Approach to Indoor Problems. Indoor Air 1998;8(Suppl 4):32-9.

7. Reijula K, Sundman-Digert C. Assessment of indoor air problems at work with a questionnaire. Occup Environ Med 2004;61(1):33-8.

8. Chow T, Yang X. Performance of ventilation system in a nonstandard operating room. Building Environ 2003;38:1401-11.

9. Chow T, Yang X. Ventilation performance in the operating theatre against airborne infection: numerical study on an ultra-clean system. J Hosp Infect 2005;59(2):138-47. 
10. Liu Y, Moser A, Harimoto K. Numerical study of airborne particle transport in an operating room. Int J Ventilation 2003;2:103-10.

11. Nordstrom K, Norback D, Akselsson R. Effect of air humidification on the sick building syndrome and perceived indoor air quality in hospitals: a four month longitudinal study. Occup Environ Med 1994;51(10):683-8.

12. Jaakkola JJ, Miettinen P. Ventilation rate in office buildings and sick building syndrome. Occup Environ Med 1995;52(11):709-14.

13. Seppanen OA, Fisk WJ. Summary of human responses to ventilation. Indoor Air 2004;14(Suppl 7):102-18.

14. Wargocki P, Sundell J, Bischof W, Brundrett G, Fanger PO, Gyntelberg F, et al. Ventilation and health in non-industrial indoor environments: report from a European multidisciplinary scientific consensus meeting (EUROVEN). Indoor Air 2002;12(2):113-28.
15. Lahtinen M, Sundman-Digert C, Reijula K. Psychosocial work environment and indoor air problems: a questionnaire as a means of problem diagnosis. Occup Environ Med 2004;61(2):143-9.

16. Niemelä R, Rautio S, Hannula M, Reijula K. Work environment effects labor productivity; an intervention study in a storage building. Am J Ind Med 2002;46:328-35.

17. Seppanen O, Fisk WJ. Ventilation and performance in office work. Indoor Air 2006;16(Suppl 7):102-18.

18. Beggs CB, Kerr KG, Noakes CJ, Hathway EA, Sleigh PA. The ventilation of multiple-bed hospital wards: review and analysis. Am J Infect Control 2008;36(4):250-9.

19. Abdel Hameed AA, Yasser IH, Khoder IM. Indoor air quality during renovation actions: a case study. J Environ Monit 2004;6(9):740-44.

20. Haiduven D. Nosocomial aspergillosis and building construction. Med Mycol 2008;25:1-7.

This work is available in Open Access model and licensed under a Creative Commons Attribution-NonCommercial 3.0 Poland License - http://creativecommons.org/ licenses/by-nc/3.0/pl/deed.en. 